\title{
Sistem Presentasi Cerdas Menggunakan Pengenalan Gerakan Tangan Berdasarkan Klasifikasi Sinyal Electromyography (EMG)
}

\author{
${ }^{1}$ Dedy HidayatKusuma, ${ }^{2}$ Moh. NurShodiq \\ ${ }^{1,2}$ TeknikInformatika, PoliteknikNegeriBanyuwangi \\ ${ }^{1,2}$ Banyuwangi, Indonesia \\ E-mail :1dedy@poliwangi.ac.id; ${ }^{1}$ noer.shodiq@poliwangi.ac.id
}

Abstrak-Perkembangan teknologi untuk mendukung sistem pembelajaran saat ini berlangsung sangat cepatsehingga muncul teknologi inovasi yang interaktif untuk tren pendidikan. Salah satu teknologi yang diimplementasikan adalah aplikasi presentasi interaktif dalam kelas multimedia atau sistem presentasi cerdas. Teknologi ini memungkinkan untuk mengontrol presentasi dengan cara alami dengan gerakan tangan mereka. Pengenalan inidapat menggantikan peran dan fungsi mouse yang konvensionaluntuk memfasilitasi kinerja guru dalam menerapkan teknologi interaktif di dalam kelas. Untuk membangun sistem presentasi cerdas ini dibagi menjadi beberapa bagian yaitu: 1)Sensor pengenalan gerakan lengan dengan menggunakan Myo armband; 2) Hand gesture recognition atau pengenalan pergerakan tangan yang dilakukan beberapa langkahmeliputi: a) pengambilan data berbasis realtime dan wireless; b) ekstraksi fitur; c) klasifikasi menggunakan artificial neural network; dan 3) Presentasicerdas, merupakan sistem presentasi yang dapat memahami perilaku manusia dan memberikan presentasi yang interaktif. Manfaat yang diharapkan dari hasil penelitian ini adalah, dengan dibangunnya sistem presentasi cerdas menggunakan pengenalan gerakan tangan berdasarkan klasifikasi dari sinyal electromyography, 1) Membuat presentasi lebih efisien, menarik dan lebih mudah untuk dipahami, dan juga membuat diskusi lebih interaktif dan meningkatkan komunikasi; 2) Membantu penyaji materi dalam memaparkan materi dengan menggunakan sistem kontrol presentasi berdasarkan gerakan tangan.

Kata Kunci-System Presentasi Cerdas, Klasifikasi, Myo Armband

Abstract-Technological developments to support the current learning system are so fast that there is an interactive innovation technology for educational trends. One of the technologies implemented is an interactive presentation application in a multimedia class or smart presentation system. This technology makes it possible to control the presentation in a natural way with their hand movements. This introduction can replace conventional mouse roles and functions to facilitate teacher performance in applying interactive technology in the classroom. To build this intelligent presentation system, it is divided into several parts: 1) Recognition sensor arm movement using Myo armband; 2) Hand gesture of hand movements made several steps include: a) data retrieval based on realtime and wireless; b) feature extraction; c) classification using artificial neural network; and 3) Smart presentation, is a presentation system that can understand human behavior and provide interactive presentations. The expected benefits of the results of this study are, with the construction of intelligent presentation systems using hand-gesturing recognition based on the classification of electromyography signals, 1) Make presentations more efficient, engaging and easier to understand, and also make the discussion more interactive and improve communication; 2) Assists the presenter of material in exposing the material by using a presentation control system based on hand gestures.

Keywords—Smart Presentation System, Classification, Myo Armband 
INTENSIF, Vol.2 No.1 February 2018

ISSN: 2580-409X (Print) / 2549-6824 (Online)

Website: http://ojs.unpkediri.ac.id/index.php/intensif

\section{PENDAHULUAN}

Perkembangan teknologi untuk mendukung sistem pembelajaran saat ini berlangsung sangat cepat. Sehingga, muncul teknologi inovasi yang interaktif untuk tren pendidikan. Salah satu teknologi yang diimplementasikan adalah aplikasi presentasi interaktif dalam kelas multimedia atau sistem presentasi cerdas. Teknologi ini memungkinkan untuk mengontrol presentasi dengan cara alami dengan gerakan tangan mereka. Pengenalan ini, dapat menggantikan peran dan fungsi mouse yang konvensional, dan memfasilitasi kinerja guru dalam menerapkan teknologi interaktif di dalam kelas [1],[2].

Para peneliti telah melakukan banyak penelitian tentang teknologi yang merapkan teknologi multimedia interaktif pada presentasi, diantarana adalah pengenalan gerakan tangan untuk mengontrol presentasi menggunakan komputer vision [1], tingkat akurasi sistem pengenalan gerakan menggunakan komputer vision ini, sangat bergantung pada posisi keberadaan presenter terhadapat sensor kamera, sehingga, keberadaan presenter sangat terbatas, karena sudah ditentukan dengan kapabilitas sensor.Penelitian selanjutnya yaitu tentang pengenalan suara untuk mengontrol multimedia menggunakan sensor suara. Pengenalan suara ini masih bergantung pada database [3].

Untuk mengatasi masalah ini maka kami mengusulkan perangkat interaktif yang memanfaatkan sensor perpindahan dan pergerakan tangan berdasarkan sensor sinyal electromyography.Untuk membangun sistem ini, dibagi menjadi beberapa bagian yaitu: sensor pengenalan gerakan lengan dengan menggunakan Myo armband. Pengambilan data berbasis realtime dan wireless yaitu menggunakan media bluetooth. Data hasil sensor ini akan diproses beberapa langkah, langkah pertama adalah ekstraksi fitur yang menggunakan Wavelet Transform dan kemudian dilakukan klasifikasi dengan menggunakan Artificial Neural Network. Hasil klasifikasi selanjutnya diimplementasikan pada system presentasi cerdas, merupakan sistem presentasi yang dapat memahami perilaku manusia dan memberikan presentasi yang interaktif.

Manfaat yang diharapkan dari hasil penelitian ini adalah, dengan dibangunya sistem presentasi cerdas menggunakan pengenalan gerakan tangan berdasarkan klasifikasi dari sinyal electromyography, 1) Membuat presentasi lebih efisien, menarik dan lebih mudah untuk dipahami, dan juga membuat diskusi lebih interaktif dan meningkatkan komunikasi; 2) Membantu penyaji materi dalam memaparkan materi dengan menggunakan sistem kontrol presentasi berdasarkan gerakan tangan 
INTENSIF, Vol.2 No.1 February 2018

ISSN: 2580-409X (Print) / 2549-6824 (Online)

Website: http://ojs.unpkediri.ac.id/index.php/intensif

\section{METODE PENELITIAN}

Metode sistem presentasi cerdas menggunakan pengenalan gerakan tangan berdasarkan klasifikasi dari sinyal electromyography (EMG) menggunakan myo armband diperlihatkanpada Gambar 1.

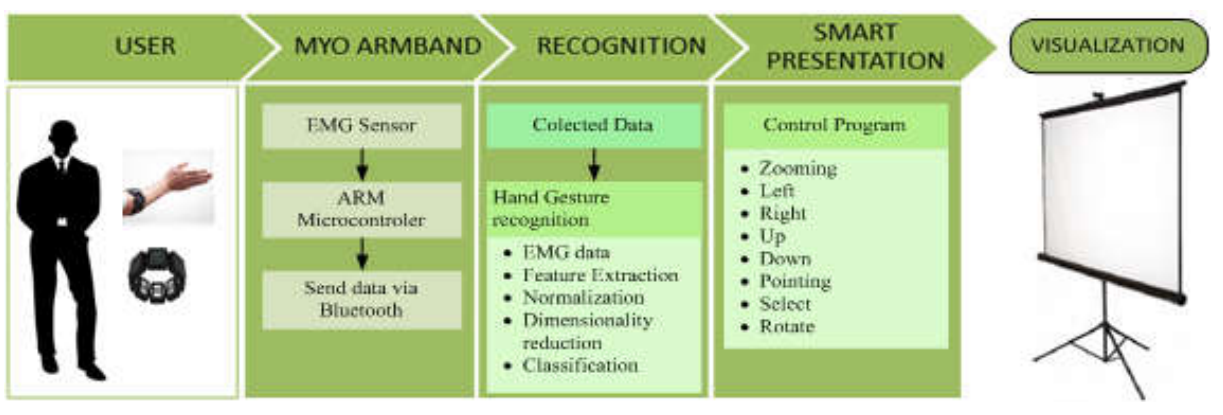

Gambar 1. DeSAin Sistem PRESENTASi CERDASMENGGUNAKAN MYO ARMBAND

Adapun penjelasan metode sistem presentasi cerdas menggunakan MYO armbandadalah sebagai berikut:

\section{A. Myo Armband}

Myo armband adalah sensor untuk pengenalan gerakan lengan. Myo armbandmempunyai delapan sensor electromyography. Armband juga menghasilkan data percepatan linear dan juga sudut angular. Serangkaian sensor EMG menghasilkan data pada frekuensi $200 \mathrm{~Hz}$. Pengirian data dari sensor EMG ke perangkat lainya (misalnya komputer, handphone) melalui bluetooth [4].

\section{B. Hand Gesture Recognition}

Pada proses pengenalan gerakan tangan terdapat beberapa proses, diantaranya adalah sebagai berikut:

a) Data EMG

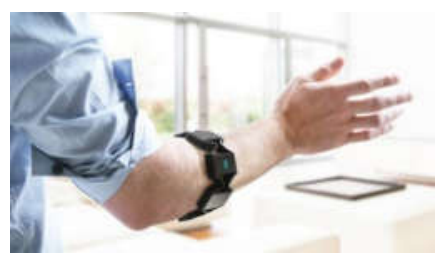

Gambar 2. ALAT MYO-ARMBAND[5]

Alat MYO terdiri dari delapan bagian sensor EMG yang terletak di sekitar lengan pengguna. Frame rate dari data EMG adalah $200 \mathrm{~Hz}$, streaming 8 saluran data 8-bit. Hasil klasifikasi tindakan yang telah ditetapkan pada data EMG adalah sebagai berikut: (1) membuat genggaman tangan, (2) menekan atau menyebarkan jari, and (3) melambaikan tangan ke kiri 
INTENSIF, Vol.2 No.1 February 2018

ISSN: 2580-409X (Print) / 2549-6824 (Online)

Website: http://ojs.unpkediri.ac.id/index.php/intensif

atau kanan[6],[7],[8]. Dalam penelitian, perangkat Myo-armband dipasang pada lengan kanan relawan seperti ditunjukkan pada gambar 2. Proses pengambilan data menggunakan library dari Myo-armband.

b) Feature Extraction

Ekstraksi fitur dari domain waktu dan domain frekuensi menjadi hal penting dalam klasifikasi pola sinyal myoelectric atau EMG [9,10,11].Metode yang paling efektif untuk extraksi fitur sinyal EMG adalah Wavelet Transform (WT) [12,13].Pada proses ekstraksi fitur, Sinyal EMG direpresentasikan sebagai fitur vektor. Hasil proses ektraksi fitur tersebut dapat dikategorikan sebagai fitur yang mempunyai dimensi tinggi, sehingga mengakibatkan permasalahan pada klasifikasi. Oleh sebab itu,fitur vektor tersebut perlu direduksi pada dimensi yang lebih rendah.Metode untuk mereduksi fitur dari fitur berdimensi tinggi ke dimensi rendah menggunakan metode reduksi fitur PCA [12].

Dalam penelitian ini digunakan empat buah fitur [13] yakni :

1. Mean absolute value (MAV), merupakan rata-rata absolut dari amplitudo sinyal EMG pada sebuah segmen. Secara matematis ditunjukkan pada persamaan 1.

$$
M A V=\frac{1}{N} \sum_{n=1}^{N}\left|X_{n}\right|
$$

2. Jumlah peak, merupakan jumlah data yang menjadi pucak dari suatu segmen pada deretan titik data. Untuk menghitung banyaknya peak digunakan persamaan 2.

$$
\rho=\Sigma_{t}^{t+T}\left[f\left(x_{t}\right)\right]
$$

dimana

$$
f\left(x_{t}\right)=\left\{\begin{array}{lc}
1, & \left(x_{(t-1)}<x_{t}\right) \text { dan }\left(x_{(t+1)}<x_{t}\right) \\
0, & \text { lainnya }
\end{array}\right.
$$

3. Willison amplitude (WAMP), merupakan jumlah hitungan untuk setiap perubahan amplitudo sinyal EMG yang melebihi ambang batas yang telah ditentukan yakni sebesar 5 $\mathrm{mV}$ sebagaimana ditunjukkan pada persamaan 4.

$$
W A M P=\sum_{t}^{t+T} f\left|x_{t+1}-x_{t}\right|
$$

dimana

$$
f\left(x_{z}\right)=\left\{\begin{array}{lc}
1, & (x)>\text { treshold } \\
0, & \text { lainnya }
\end{array}\right.
$$

Root Mean Square(RMS),merupakanperhitunganfitur untuk menentukan rasio antara tingkat tegangan langsung dan alternasinya yang dihitung dengan menggunakan persamaan 7 . 
INTENSIF, Vol.2 No.1 February 2018

ISSN: 2580-409X (Print) / 2549-6824 (Online)

Website: http://ojs.unpkediri.ac.id/index.php/intensif

$$
R M S=\sqrt{\frac{1}{N} \sum_{k=1}^{N} X_{k}{ }^{2}}
$$

c) Classification

Metode yang digunakan untuk klasifikasi dalam pengenalan pola EMG adalah Artificial Neural Network karena metode ini secara tepat dapat mengenali sinyal myoelectric [12]. Untuk mengukur kinerja dari klasifikasi, semua data EMG dibagi menjadi dua bagian, yaitu data training dan data test [14]. Kemudian uji data dengan menggunakan $k$-fold cross validation. Data training digunakan untuk membangun model klasifikasi, sedangkan data test digunakan untuk memverifikasi [13].

\section{Smart presentation}

Sistem presentasi cerdas merupakan sistem presentasi yang dapat memahami perilaku manusia dan memberikan presentasi yang nyaman dengan kealamian dan fleksibilitas yang tinggi sehingga presentasi tidak menjadi kaku [15]. Seorang penyaji materi dapat mengontrol presentasi dengan cara alami, yaitu dengan gerakan tubuh. Salah satu gerakan tubuh yang digunakan adalah gerakan tangan. Sistem ini mampu mengontrol dan berinteraksi dengan berbagai aplikasi seperti aplikasi presentasi seperti Microsoft Powerpoint. Gerakan tangan ini digunakan untuk mengatur sistem presentasi seperti gerakan mouse, next, previous, scroll up, scroll down, select dan menu [2],[16].

\section{HASIL DAN PEMBAHASAN}

\subsection{Dataset Pengujian}

Jumlah relawan yang berpartisipasi untuk pengambilan sample data berjumlah 12 orang mahasiswa dengan masing-masing relawan diambil 5 jenis pose gerakan tangan yakni menggenggam, meregang, wave in, wave out, dan relaks sehingga total dilakukan $5 \times 12$ pengambilan data pose. Gambar 3 memperlihatkan sinyal EMG pada sensor EMG 3 ketika relawan dalam pose meregangkan tangan.

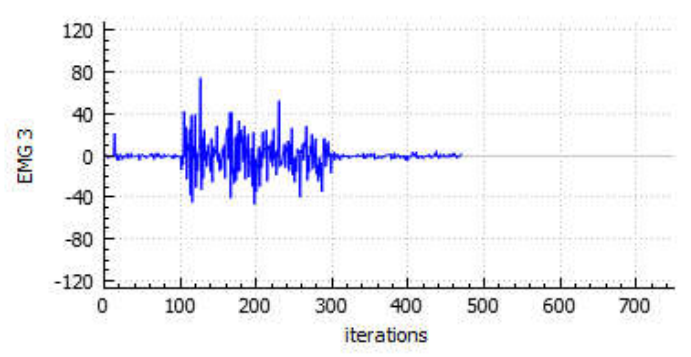

Gambar 3. SINYAL EMG UNTUK POSE MEREGANG 
INTENSIF, Vol.2 No.1 February 2018

ISSN: 2580-409X (Print) / 2549-6824 (Online)

Website: http://ojs.unpkediri.ac.id/index.php/intensif

Normalisasi data selanjutnya dilakukan dilakukan sehingga didapatkan hasil normalisasi pada gambar 4.

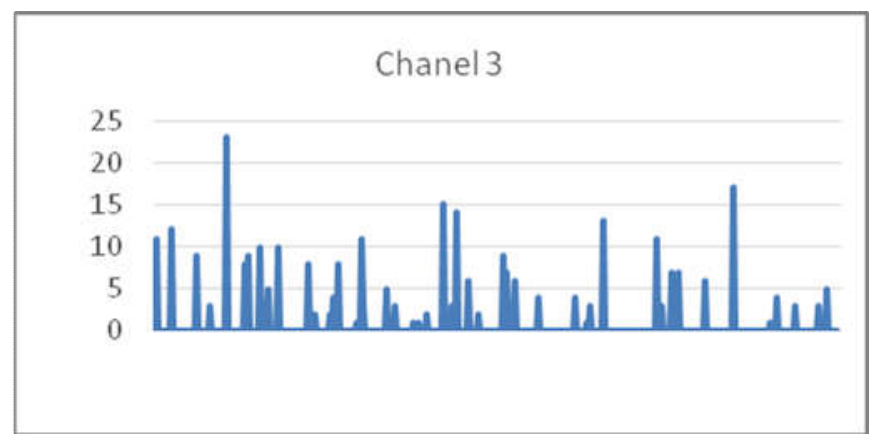

Gambar 4. SINYAL EMG YANG DINORMALISASI

Data EMG yang sudah ternormalisasi pada sebuah segmen selanjutnya dilakukan ekstraksi fitur guna mendapatkan empat nilai fitur yakni MAV, jumlah peak, WAMP, dan RMS. Total $5 \times 12$ atau 60 dataset yang dihasilkan dimana masing-masing dataset terdiri dari 4x8 nilai data sesuaijumlah fiturdan sensor EMG. Penentuan data latih dan data uji dilakukan secara acak dengan menggunakan $\mathrm{k}$-fold cross validation dengan $\mathrm{k}=3$, data training $66,67 \%$ dan data tes $33,33 \%$. Dengan menggunakan pendekatan tersebut maka data akan dipartisi menjadi 3 kelompok dengan masing-masing kelompok terdiri atas 4 dataset. Pada setiap eksperimen, dua dataset digunakan sebagai data training dan satu kelompok sebagai data uji.

\subsection{Pengenalan Pose GerakanTangan}

Model arsitektur jaringan syaraf tiruan yang digunakan dalam mengklasifikasikan pose gerakan tangan dalam penelitian yakni menggunakan 32 node input sesuai dengan jumlah fiturdan sensor EMG, 2 lapisan tersembunyi, dan 3 node output. Metode pelatihan menggunakan metode back propagation, learning rate 0,1dan fungsi aktivasi sigmoid. Model ANN yang digunakan ditunjukkan pada gambar 5 .

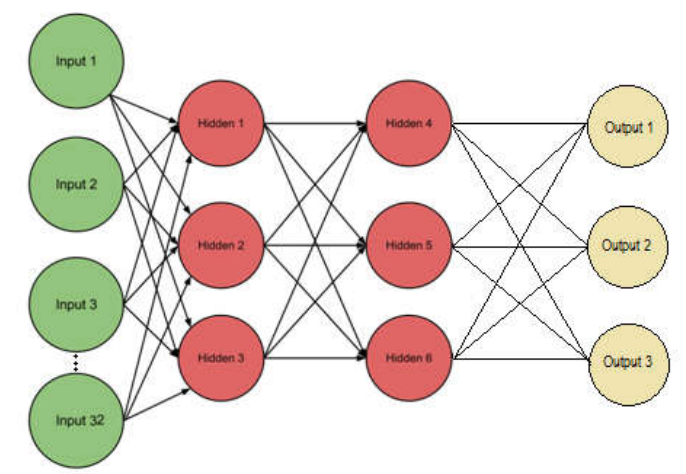

Gambar 5. MODEL ANN YANG DIGUNAKAN 
INTENSIF, Vol.2 No.1 February 2018

ISSN: 2580-409X (Print) / 2549-6824 (Online)

Website: http://ojs.unpkediri.ac.id/index.php/intensif

Tiga buah output berisikan kode biner (bernilai 0 atau 1) di mana setiap pasangan output mewakili kelas pose sebagaimana ditunjukkan pada Tabel 1.

Tabel 1. PEngKODEAN OUTPUT

\begin{tabular}{ccccc}
\hline \hline No & Output 1 & Output 1 & Output 1 & Kelas Pose \\
\hline 1 & 0 & 0 & 0 & Menggenggam \\
\hline 2 & 0 & 0 & 1 & Relax \\
\hline 3 & 0 & 1 & 0 & Wave in \\
\hline 4 & 0 & 1 & 1 & Wave out \\
\hline 5 & 1 & 0 & 0 & Meregang \\
\hline 6 & 1 & 0 & 1 & \\
\hline 7 & 1 & 1 & 0 & Unidentified \\
\hline 8 & 1 & 1 & 1 & \\
\hline
\end{tabular}

Hasil pengujian menggunakan $\mathrm{k}$-fold cross validation dengan $\mathrm{k}=3$ diperoleh hasil seperti ditunjukkan pada tabel 2.

Tabel 2. CONFUSION MATRIX 3-FOLD CROSS VALIDATION

Jenis pose $\quad$ Output sistem

(a) (b) (c) (d) (e) Unidentified

class

\begin{tabular}{llcccccc}
\hline (a) & Genggam & 10 & 0 & 0 & 0 & 2 & 0 \\
\hline (b) & Relax & 1 & 11 & 0 & 0 & 0 & 1 \\
\hline (c) & Wave in & 1 & 0 & 10 & 1 & 0 & 0 \\
\hline (d) & Wave out & 0 & 1 & 1 & 9 & 0 & 1 \\
\hline (e) & Meregang & 2 & 0 & 0 & 0 & 9 & 1 \\
\hline
\end{tabular}

Dari confusion matriks pada tabel 2 maka dapat dihitung akurasisebesar 81,67\%, reratapresisisebesar $85,16 \%$, dan reratarecall sistem sebesar $83,66 \%$.

\subsection{Aplikasi Presentasi Cerdas}

Pada Gambar 6ditunjukkan diagram alir sederhana tentang pembuatan konektor myo arm dan aplikasi di operasi sistem windows. Script program dapat ditulis menggunakan bantuan text editor, misalnya notepad, kemudian disimpan dengan extension *.myo. 
INTENSIF, Vol.2 No.1 February 2018

ISSN: 2580-409X (Print) / 2549-6824 (Online)

Website: http://ojs.unpkediri.ac.id/index.php/intensif

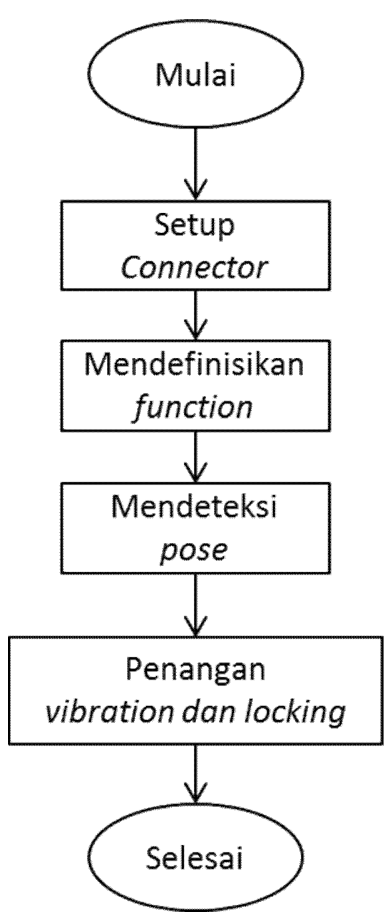

Gambar 6. ALUR PEMBUATAN SCRIPT MYO

Setelah instalasi perangkat dan pengkodean aplikasi selesai dilakukan maka dilakukan running test presentasi. Untuk menghubungkan perangkat Myoarmband dengan aplikasi MS Power Point maka dijalankan script seperti pada Gambar 7.

\begin{tabular}{|c|}
\hline scriptId $=$ 'com.thalmic.scripts.presentation' \\
scriptDetailsUrl = 'https://market.myo.com/app/5474c658e4b0361138df2a9e' \\
scriptTitle = 'PowerPoint Connector' \\
function onForegroundWindowChange(app, title) \\
local uppercaseApp = string.upper(app) \\
return platform == "MacOS" and app == "com.microsoft.Powerpoint" or \\
platform == "Windows" and (uppercaseApp == "POWERPNT.EXE" or \\
uppercaseApp == "PPTVIEW.EXE") \\
end
\end{tabular}

Gambar 7. SCRIPT KONEKSI MS POWER POINT

Pergantian halaman presentasi menggunakan pose waveIn untuk mundur dan pose waveOut untuk maju seperti script pada Gambar 8.

pose $=$ conditionallySwapWave(pose)
if pose == "waveIn" then
shuttleDirection = "backward"
else
shuttleDirection = "forward"
end

Gambar 8. SCRIPT KONTROL PRESENTASI 
INTENSIF, Vol.2 No.1 February 2018

ISSN: 2580-409X (Print) / 2549-6824 (Online)

Website: http://ojs.unpkediri.ac.id/index.php/intensif

\section{KESIMPULAN DAN SARAN}

Dari hasil penelitian yang dilakukan dapat disimpulkan bahwa telah dibangun suatu model ANN untuk mengenali sinyal EMG dari pose gerakan tangan dengan menggunakan 32 node input, 2 hidden layer, learning rate 0,1 , metode training back propagation, fungsi akivasi sigmoid, dan 3 output. Model yang diusulkan memiliki akurasi sebesar 81,67\%, rata-rata presisi $85,16 \%$ dan recall $83,66 \%$. Beberapa saran untuk pengembangan penelitian ini yaitu terkait pemasangan sensor EMG Myo-armband pada lengan harus dilakukan dengan tepat karena akan berpengaruh pada kualitas pembacaan sinyal EMG yang dihasilkan. Penggunaan metode klasifikasi lainnya dapat dicoba untuk mendapatkan unjuk kerja yang lebih baik dan Hasil klasifikasi dapat dikembangkan sehingga tidak hanya digunakan untuk mengontrol presentasi saja.

\section{UCAPAN TERIMAKASIH}

Ucapan terimakasih kami sampaikan kepada Direktorat Riset dan Pengabdian Masyarakat (DRPM) Kemenristekdikti yang telah mendanai penelitian ini melalui skema Penelitian Dosen Pemula (PDP).

\section{DAFTAR PUSTAKA}

[1] Sukaridhoto, S., Assidiqi, M.H., Salim, N.N.A., 2014. Simple Interactive Projector Based on Hand Gesture Movement. International Electronics Symposium (IES) 2014. ISBN : 978-602-0917-14-6

[2] Wardhany, V.A., kurnia, M.H., Sukaridhoto, S., Sudarsono, A., Pramadihanto, D. 2015. Smart Presentation System using Hand Gestures and Indonesian Speech Command. International Electronics Symposium (IES) 2015 Page:68 - 72

[3] Wardhany, V.A., Sukaridhoto, S., Sudarsono. 2014. Indonesian Automatic Speech Recognition For CommandSpeech Controller Multimedia Player. EMITTER International Journal of Engineering TechnologyVol.2, No.2, December 2014

[4] Hidayat, A.A., Arief, Z., Happyanto, D.C. 2015. LOVETT Scaling with Flex Sensor and MYO Armband for Monitoring Finger Muscles Therapy of Post-Stroke People. International Journal of Engineering Technology Vol.3, No. 2, December 2015

[5] Thalmic lab. MYO armband tech specs, 2016. Gestures and Motionhttps:https://www.myo.com/techspecs 
INTENSIF, Vol.2 No.1 February 2018 ISSN: 2580-409X (Print) / 2549-6824 (Online)

Website: http://ojs.unpkediri.ac.id/index.php/intensif

[6] Boyali, A., Hashimoto, N., Matsumoto, O. 2015. Spectral Collaborative Representation Based Classification by Circulants and its Application to Hand Gesture and Posture Recognition from Electromyography Signals. Int'l Conf. IP, Comp. Vision, and Pattern Recognition (IPCV'15)

[7] Nymoen, K., Haugen, M.R., Jensenius, A.R. 2015. MuMYO — Evaluating and Exploring the MYO Armband for Musical Interaction. Proceedings of the International Conference on New Interfaces for Musical Expression, Baton Rouge, LA, USA, May 31-June 3, 2015

[8] Boyali, A., Hashimoto, N., 2016. Spectral Collaborative Representation based Classification for Hand Gestures recognition on Electromyography Signals. Biomedical Signal Processing and Control Volume 24, February 2016, Pages 11-18

[9] Phinyomark, A., Phukpattaranont, P., Limsakul, C. 2011. Electromyography (EMG) Signal Classification Based on Detrended Fluctuation Analysis. Fluctuation and Noise Letters Vol. 10, No. 3 (2011) 281-301

[10] Phinyomark, A., Phukpattaranont, P., Limsakul, C. 2012. Feature reduction and selection for EMG signal classification. Expert Systems with Applications 39 (2012) $7420-7431$

[11] Phinyomark, A., Thongpanja, S., Quaine, F., Laurillau, Y., Limsakul, C., Phukpattaranont, P. 2013. Optimal EMG Amplitude Detectors for Muscle-Computer Interface. Electrical Engineering/Electronics, Computer, Telecommunications and Information Technology (ECTI-CON), 2013 10th International Conference on pp.1-6

[12] Rubana, H. C., Mamun B. I., Alauddi, M., Ashrif A. A. B., Kalaivani C., Chang G., 2013. Surface Electromyography Signal Processing and Classification Techniques. Sensors 2013, 13, 12431-12466; doi:10.3390/s130912431

[13] Subasi, Abdulhamit. 2012. Classification of EMG signals using combined features and soft computing techniques. Applied Soft Computing 12 (2012) 2188-2198

[14] Peters, T. 2014. An Assessment of Single-Channel EMG Sensing for Gestural Input. Online: http://www.cs.dartmouth.edu/ traviswp/papers/TR/peters_emg_14.pdf diakses pada tanggal 3 mei 2016

[15] Le, H., Nguyen K.C., Pham, T., Nguyen, V., Tran, M. 2013. Multimodal Smart Interactive Presentation System. Human-Computer Interaction, Part IV, HCII 2013, LNCS 8007, pp. 67-76, 2013. Springer-Verlag Berlin Heidelberg

[16] Butnariu, S., Girbacia, F. 2012. Development Of A Natural User Interface For Intuitive Presentations In Educational Process. The 8th International Scientific Conference eLearning and software for Education, Bucharest, April 26-27, 2012 